\title{
Posthumane visioner:
}

\section{En postkønnet eller kvindelig cyberkultur?}

Af Nina LyKKe

Avtiklen diskutever to feministiske cyberkultur-teoretikere, Donna Haraway og Sadie Plant, og deres postbumane kons-, kultur-og teknologikritik. Den konfronterer Haraways opsporing af en postkønnet kropslighed og subjektivitet $i$ kyborg-figuren med Plants Irigaray-inspirerede forseg pai at indskrive det kvindelige subjekt $i$ cyberspace.

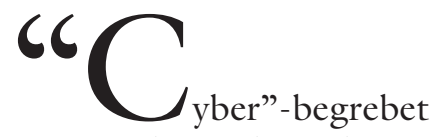

og ordsammensætninger, hvori det indgår "cyberspace", "cyborg/kyborg" etc. - bliver mere og mere almindelige. Vi lever i en "cyberkultur". Denne artikel er en køns-, kultur- og teknologikritisk refleksion over denne kulturs problemer og muligheder. Jeg vil især se på potentialerne. Men da problemerne ikke blot kan lades ude af betragtning, vil jeg tage udgangspunkt i en af mine idiosynkrasier; et anomymt og grimt, men typisk billede (se billedet side 45).

Billedet er ikke et man bider mærke i, men de fleste vil nok nikke genkendende til typen. Den slags billeder findes i utallige rapporter, konferencematerialer og oplysende skrifter om IT. Mit eksempel stammer fra en Betonkning om Teknologistøttet Fjernundervisning (Undervisningsministeriet 1993). Her formuleres vidtgående visioner om brug af informationsteknologi i undervisningen på alle niveauer i det danske uddannelsessystem; fra korte kurser for ufaglærte til universitetsuddannelser. Der er 
magt bag betænkningens ord. Den er udformet af et ekspertpanel med deltagelse fra universiteterne og teknologiverdenen og blev fulgt op med store bevillinger til et Center for Teknologistøttet Uddannelse, der skulle virkeliggøre visionerne.

Hvad er karakteristisk for billederne i en sådan toneangivende betænkning? Æstetisk er der ikke noget at råbe hurra for. Billederne er kedelige og blot sat ind for at bryde den monotone rapporttekst. Men i al deres uæstetiske anonymitet cementerer de umærkeligt en stereotyp. For hvilket køn har de personer, der skal illustrere Danmarks fremtid i den fagre, nye IT-verden med fri og demokratisk adgang til information, viden og uddannelse for alle? Hvad lærernes køn angår, er der ingen tvivl. De, der skal guide os ind i den ny verden, har kraftig skægvækst. Eleverne er mere ubestemmelige. Men de, som vi ser bedst, har umiskendeligt en drengefrisure!

Billedet er en interessant kulturmarkør. I al sin anonymitet illustrerer det en tagetfor-givet-bevidsthed hos afsenderen - og måske også hos modtageren, for som modtagere registrerer vi vel som regel blot tilstedeværelsen af sådanne billeder uden egentlig at tage notits af dem. I sin grå kedsommelighed understreger billedet diskret, men umiskendeligt de maskuline konnotationer, der præger toneangivende diskurser om den ny cyberverden. Set fra et feministisk perspektiv, peger det på, at der er brug for en alternativ køns-, kultur- og teknologikritisk tænkning omkring "cyberkulturen".

For at give et indspil til denne debat vil jeg diskutere to feministiske teoretikere, Donna Haraway og Sadie Plant. Begge repræsenterer en forfriskende, feministisk nytænkning. De forfalder nemlig ikke til blot at begræde kvinders fravær i de maskulint konnoterede diskurser om "cyberkulturen". Tværtimod går de et vigtigt skridt videre. De dekonstruerer den maskuline dominans og artikulerer andre visioner og potentialer.

Jeg har i en tidligere artikel i Kvinder,
Køn og Forskning (Lykke 1996) diskuteret, hvordan Haraway artikulerer en postmoderne feminisme, der epistemologisk positionerer sig med udgangspunkt i den kropsligt og subjektivt mangetydige "kyborg"figur $\mathrm{i}$ stedet for $\mathrm{i}$ et essentialistisk "kvinde"-begreb. Her vil jeg konfrontere Haraway med Plant, der ligeledes anlægger utraditionelle og innovative, feministiske synsvinkler på “cyberkulturen”. Fælles for Haraway og Plant er en posthuman indfaldsvinkel, der afviser, at begreber som "det menneskelige" og "det naturlige" kan anvendes som udgangspunkt for en feministisk køns-, kultur- og teknologikritik. Samtidig er de også forskellige. Haraway er tiltalt af de muligheder for en postkønnet kropslighed og subjektivitet, som "kyborg"-figuren rummer, mens Plant med inspiration fra Luce Irigaray vil indskrive det kvindelige subjekt i cyberspace.

Mit formål med artiklen er at diskutere disse ligheder og forskelle med udgangspunkt $i$ to nye værker: Haraways Modest_Witness@Second_Millennium.FemaleMan@_Meets_OncoMouseTM (1997) og Plants Zeros + Ones. Digital Women + The New Technoculture (1997). Afslutningsvist profilerer jeg desuden Haraways og Plants posthumane køns-, kultur- og teknologikritik ved at forholde den til en dansk "kyborg"-roman, Dorrit Willumsens Programmeret til karlighed (1981).

\section{TO AKTUELLE METAFORER:}

\section{“KYBORGER" OG “CYBERSPACE"}

Begreberne "kyborger" og "cyberspace" kan betragtes som metaforer, der er forankret i aktuelle kulturelle, sociale, politiske og teknologiske transformationsprocesser. Når jeg i overensstemmelse med Markussen (1997) pointerer det metaforiske aspekt, er det for at understrege, at begge begreber fungerer som evokative epicentre for generering af nye sociokulturelle forståelser og vidtforgrenede fortællinger. "Cyberspace" henviser til udviklingen af globale kommu- 


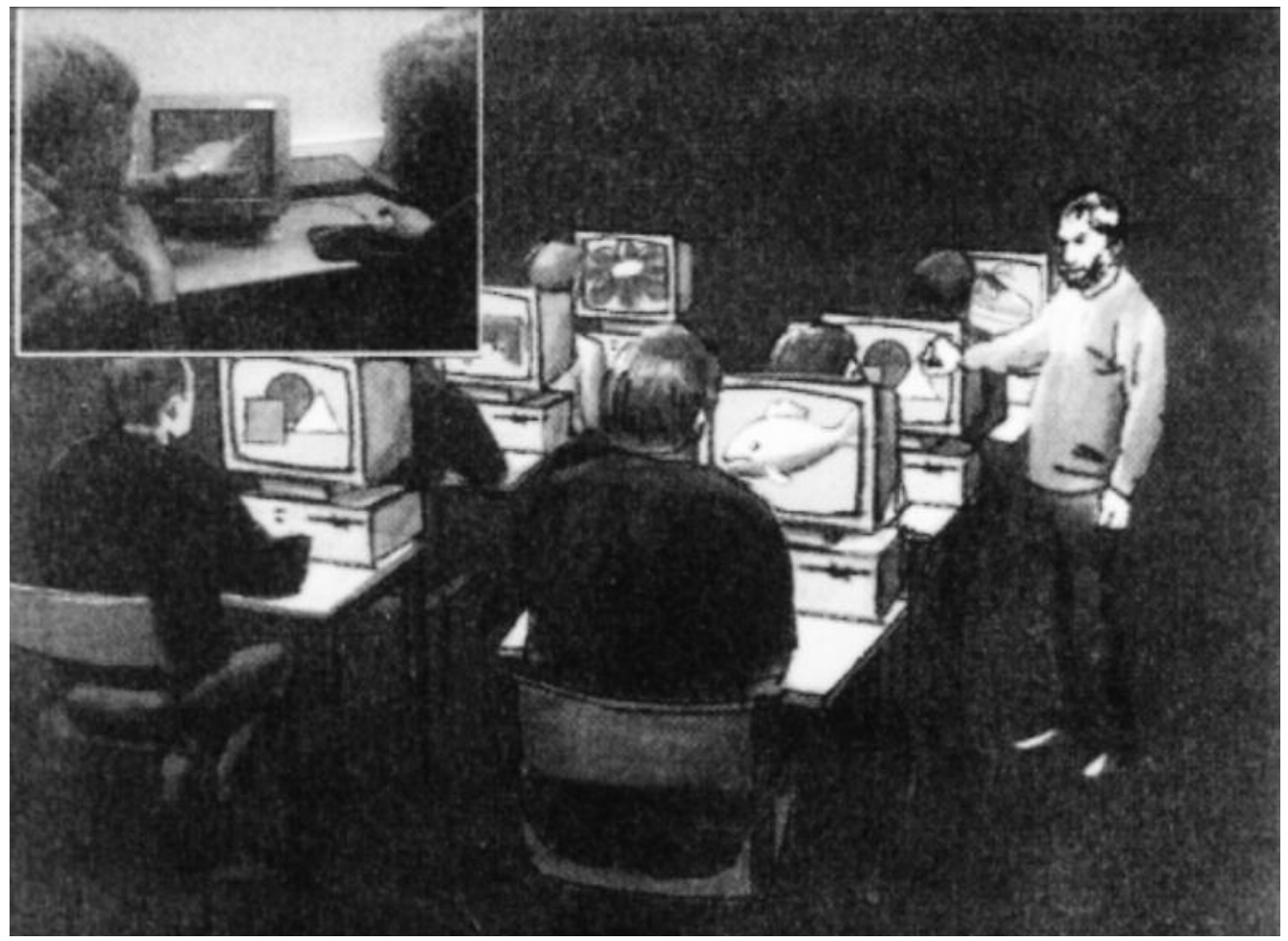

Statslige diskurser om kon $i$ den fagre nye IT-perden. (Fra Undervisningsministeriets betonkning om teknologistottet fjernundervisning, Betenkning 1253, 1993.) 
nikationsnet som Internettet. "Kyborg" betegner en kybernetisk organisme - en organisme, hvis fysiologiske funktioner modificeres/transformeres/simuleres af tekniske styresystemer, en menneske- eller dyremaskine. Men til begge begreber knytter sig samtidig et bredt metaforisk betydningsfelt, der er genereret ved tætte forbindelser dels til den aktuelle teknovidenskabelige udvikling af informationsteknologi, bioteknologi mv. og dels til science fiction genren.

I den brede betydning tematiserer " $k y$ borger" og "cyberspace" væsentlige skred i grundlaget for den menneskelige virkelighedsopfattelse. For modernitetens videnskabeligt skolede subjekt var det afgørende at kunne skelne mellem facts og fiktion og mellem kultur og natur, men med den aktuelle sociotekniske udvikling sættes der nogle afgørende spørgsmålstegn ved disse skel. De dekonstrueres; deres betydninger bliver flydende. I de interaktive, elektroniske kommunikationsrum, som "cyberspace" refererer til, bliver skellet mellem det faktuelle og det fiktive flydende. "Virkeligheden" bliver "virtuel", jfr. begrebet "virtual reality". I den kybernetiske organisme, maskin-mennesket, maskin-dyret, som "kyborg"-begrebet henviser til, dekonstrueres grænsen mellem det kulturlige og det naturlige, mellem menneske, dyr og maskine. Disse grænsenedbrydninger er vigtige for at forstå Haraways og Plants posthumane feminisme; hos begge giver de afsæt til nytænkning omkring kønnet.

\section{Haraway og Plant - FÆLlestræk}

For både Haraway og Plant er cyberkulturen noget, som vi ikke kan vælge til eller fra. Vi lever i mellemrummene mellem cyberspace's "virtuelle" og den "virkelige" verden, og vores kroppe er "kyborgificerede", omskabt til kyborg-kroppe. Vi er in medias res, "inde i" cyberkulturen, og derfor er det illusorisk at diskutere teknologi fra et "udenfor". Hverken den "rene" menneskeligheds position (humanistisk tekno- logikritik) eller den "rene" naturs position (spirituel økofeminisme, dybdeøkologi etc.) er gangbare ifølge Haraway og Plant.

I sin nyeste bog illustrerer Haraway (1997) denne "inde i"-position ved at situere bogens udsigelse - den afsender-position, hvorfra der tales - som en e-mail adresse. Plant anvender i sin seneste bog (1997) en lidt anden tekstuel strategi, der også peger i retning af dette "inde i”. Hun opløser det tekstuelle hierarki, som traditionelt er indbygget $\mathrm{i}$ videnskabelige tekster. Bogen er skrevet som en "perlerække" af korte tekststykker, der er bundet metonymisk og associativt sammen, så teksten kommer til at minde om en surfe-tur på Internettet.

Når et "udenfor" ikke kan bruges som afsæt for en kombineret køns-, kultur- og teknologikritik, bliver målestokken for Haraway og Plant en anden. Begge tager i stedet afsæt i spørgsmålet om, hvordan de, som Haraway kalder "inappropriate/d others", de marginaliserede, de andre, de der har skæve vinkler, kan være med til at sætte dagsordenen "inde i" cyberkulturen. Med begrebet "inappropriate/d others" sigter Haraway (1992) i forlængelse af den amerikansk-vietnamesiske kunstner og teoretiker Trinh Minh-ha til alle dem, der er marginaliseret af "the social relations of science and technology" (Haraway 1991, 170), dvs. de hegemoniske barrierer, der er skabt af sociotekniske magtforhold og sociokulturelle hierarkier, konstrueret omkring akser som køn, race, klasse. Alle disse "andre" taler fra "skæve" vinkler i forhold til det "universelle man(d)", dvs. det hvide, maskuline, økonomisk velfunderede subjekt. Teknologikritik bliver på den baggrund et spørgsmål om at sætte dagsordenen fra disse skæve vinkler.

Både Haraway og Plant anlægger kritiske vinkler på cyberkulturen og de sociotekniske magtforhold, den er indlejret $i$, men samtidig finder de nogle, feministisk set, interessante potentialer i cyberverdenen - i den måde, den fremmer en posthuman kultur på. Det er en kultur, der med et udtryk, som jeg låner fra den amerikanske robotfor- 
sker Rodney Brooks, besinder sig på en "retreat from human specialness", 1 dvs. besinder sig på at holde op med arrogant at insistere på menneskets (alias det "universelle $\operatorname{man}(\mathrm{d}) \mathrm{s}$ ") helt særlige og ophøjede placering over alle andre skabninger - en placering, der har legitimeret en reduktion af den ikke-menneskelige materie til ressource og objekt.

Vejen til denne posthumane kultur går for både Haraway og Plant gennem dekonstruktive bevægelser, der finder sted i de væv af subjekt, køn, etnicitet, klasse, krop, natur, teknologi, videnskab, samfund, som vi som posthumane subjekter er situeret "inde i". Men i artikuleringen af kønnets betydning i disse dekonstruktive bevægelser adskiller de to teoretikere sig noget fra hinanden.

\section{HARAWAY: KYBORGEN SOM DEKONSTRUKTIV FIGUR}

For at finde potentialer i cyberverdenen tager Haraway udgangspunkt i dens beboere, kyborgerne, menneske- eller dyremaskinerne. De potentialer, hun ser i kyborg-figuren, ligger i, at den dekonstruerer en række af de grænser, som humanismen har konstrueret for at ophøje det "universelle $\operatorname{man}(\mathrm{d})$ " i opposition til alt det, der er blevet sat som "det andet": naturen, kvinden, den etniske anden, kroppen, maskinen. Ved at dekonstruere alle disse grænser, udviskes oppositionen og dermed hierarkiet mellem det "universelle man(d)" og "det andet". I stedet for en opposition mellem kultur og natur sætter kyborgen dagsordenen for en genopfunden natur (en "reinvention of nature", Haraway 1991) og for en sammensmeltning af menneske og maskine. Endvidere bevæger kyborg-figuren os mod en postkønnet verden. Jeg har i min tidligere artikel om Haraway (Lykke 1996) gjort nærmere rede for hendes kyborg-figur og vil derfor her nøjes med kort at eksemplificere, hvordan hun arbejder med dens dekonstruktive bevægelser ved at inddrage de kyborger, der er repræsenteret i den e-mailadresse, som udgør titlen på hendes nyeste bog (Haraway 1997).

E-mail-adressen Modest_Witness@Second_ Millennium.FemaleMañ__Meets_Onco Mouse $^{\mathrm{TM}}$. består af en række centrale ikoner, hvis sammenstilling eller konfiguration repræsenterer en dekonstruktion. Genstanden for dekonstruktionen er første led i adressen: "det beskedne vidne fra det andet millennium". Som tidsangivelsen angiver, er det en historisk figur. Det er en instans, som blev opfundet for, at den moderne (natur)videnskab kunne påberåbe sig objektivitet. Haraway sporer udtrykket "modest witness" tilbage til en af denne videnskabs grundlæggere, Robert Boyle (1627-91) (Haraway 1997, 23ff.), men understreger også, at vidnet her mod slutningen af årtusindet stadig er en magtfuld figur. Det er den positivistisk orienterede naturvidenskabs "neutrale iagttager", der bekræfter, at et forsøg, en naturvidenskabelig iagttagelse er gentagelig. Vidnet er fagkollegaen, den intersubjektive konsensus i forskersamfundet. At dette vidne af Boyle kaldes "beskedent", er for Haraway dybt ironisk. Vidnet er tværtimod det magtfulde alibi, når videnskaben påberåber sig at kunne udsige objektive sandheder om verden med henblik på at instrumentalisere den som ressource. Haraway har andetsteds brugt udtrykket "god-trick" (Haraway 1991, 189) til at karakterisere denne position. I litteraturvidenskaben kendes den som en over vandende svævende, alvidende fortæller i gammeldags romaner, dvs. den fortæller, der som Gud kan gennemskue alt og alle, men som selv er usynlig: krops- og ansigtsløs. Historisk set er der, understreger Haraway (1997, 28ff.), også tale om en i allerhøjeste grad kønnet position. Det er den umarkerede og uspecificerede kategori "man", det "universelle man $(\mathrm{d}) \mathrm{s}$ " position, der identificeres med det hvide, økonomisk velfunderede maskuline subjekt.

Det "beskedne" vidne dekonstrueres hos Haraway ved at blive bragt i berøring med 
to nye vidner: to forskellige kyborger. Den ene er "the female man" fra den feministiske science-fiction-forfatter Joanna Russ' roman af samme navn (Russ 1975). Det andet kyborg-vidne er onkomusen, en genetisk manipuleret museart, der er konstrueret med henblik på at kunne bruges som forsøgsdyr i kræftforskningen. Musen med kræftgenet blev - som det første patenterede dyr i verden - annonceret til salg af firmaet Du Pont i 1990.

“The female man" fra Russ' roman inddrages som en figur, der unddrager sig enhver form for traditionel køns-, natur- og oprindelseskonstruktion. Romanen handler om fire kvindelige cloner (Janet, Joanna, Jeannine og Jael), der udsættes for dybt forskellige kulturpræg, og som derfor uanset at de er genetisk identiske - kommer til at afvige meget fra hinanden. De representerer i Haraways tolkning en postkønnet, postnaturlig, postoprindelig og postessentiel historie om tilblivelsen af et subjekt. Kønsligt er Russ' titelfigur(er), siger Haraway, en dekonstruktion og denaturalisering af historien både om "universal Man” og hans modstykke "universal Female" (Haraway 1997, 70). Romanen skaber med kyborg-figuren, "the female man", en bevidst forvirring omkring forholdet mellem køn, krop, subjekt, gener og sprog.

Tilsvarende er onkomusen, som jeg har diskuteret nærmere andetsteds (Lykke 1996), et godt eksempel på et stykke genopfunden natur, hvor grænserne mellem "original" organisme og teknologisk "udvidelse", mellem oprindelse og aktuel manifestation er blevet fuldstændigt udviskede, lige som grænserne mellem naturligt og kunstigt. Disse distinktioner er ikke længere brugbare over for onkomusen. Tingene flyder sammen. De er dekonstrueret i både materiel og diskursiv forstand.

Haraway konfronterer altså den moderne videnskabs "beskedne vidne" - den humanistiske tankes fornemste repræsentation, det rene menneske, der spiller det "gudstrick" at kunne udtale sig om alt og alle fra en ikke-kropslig og ikke-situeret position med to posthumane kyborger. Det alt andet end "beskedne" vidne degraderes ved at blive bragt i berøring med to skæve eksistenser: klonen, "the female man", og den patenterede og med varemærke-tegnet тм stemplede onkomus.

Modsat Boyles og positivismens "beskedne vidne" er disse to nye vidner situerede og kropsliggjorte; som klon og genetisk manipuleret organisme er det umuligt at sige sig fri for en kropslig forankring. Men samtidig er det også en pointe, at de to vidner unddrager sig at blive lagt fast som essens (kvindelig essens, museessens, naturens essens). De er med Baudrillards udtryk simulacra uden originaler (Baudrillard 1994). Vi bliver ikke fristet til at tage et teknologikritisk afsæt i dem som repræsentanter for en "ren, uskyldig, ubesmittet" natur. En sådan natur kender de ikke. Lige som de ved deres påtrængende kropslighed degraderer det "rene" menneskes, det "beskedne vidnes" position, distancerer de sig også utvetydigt fra den "rene" natur. Der er for dem ikke noget "udenfor"; de er i allerhøjeste grad i den tidligere omtalte in medias res-position i forhold til teknologien.

Det turde være indlysende, at når teknovidenskaben og de sociale magtforhold, der knytter sig til den, vurderes fra disse to nye vidners synsvinkler, så vil der blive tale om en anden vurdering end den, som det gamle vidne foretog. Dettes gudslignende position dekonstrueres effektivt hos Haraway af de to nye vidners skrve - posthumane, postnaturlige og postessentielle - perspektiver. Haraway kalder dette posthumane udgangspunkt for kyborg antropologi (Haraway 1997, 52) - at se fra kyborgens position.

\section{Plant: DEN POSTHumane ALLIANCE MELLEM KVINDER OG MASKINER}

Plant ser også de potentialer i den posthumane verden, som vores mere og mere inti- 
me samliv med maskinerne afføder. Lige som Haraway betragter hun cyberkulturen som formidler af en "retreat from human specialness" (jf. Brooks), men på en noget anderledes måde. Haraway lader en postkønnet figur, kyborgen, være bærer af de potentialer, der lægger op til dekonstruktion af såvel humanismens stolte menneske, det moderne subjekt, det "universelle $\operatorname{man}(\mathrm{d})$ " som den "rene", essentielle og oprindelige natur. Plant sætter omvendt fokus på en kvindelig position; hendes dekonstruktion af cyberspace som et rum, der symbolsk er centreret om maskulinitet, tager udgangspunkt i et posthumant fællesskab mellem kvinder og maskiner.

Plant er inspireret af Luce Irigaray (1974 og 1977), hvis (komplicerede og strengt taget ikke parafraserbare) opfattelse af forholdet mellem køn, krop, subjekt og skrift/tale/tekstualitet jeg derfor kort vil resumere. Ifølge Irigaray repræsenterer kvindekroppen en forskel, der gør en forskel. Det er imidlertid en forskel, som er forblevet fortrængt - som ikke er blevet hverken imaginært eller symbolsk tematiseret - af den vestlige kultur siden Platon og Aristoteles. Kvindekroppen er det andet, den materialitet (f.eks. moderkroppen, modermaterien), som kulturens maskuline subjekt udgår fra, men også fortrænger. Dette subjekt er ifølge Irigaray blevet til på baggrund af en fortrængning af det kvindelige på et både imaginært og symbolsk plan - en fortrængning, som Freuds og Lacans psykoanalyse f.eks. viser sig som et symptom på, når de diskursivt konstruerer Kvinden som mangel, ikkemand, kastreret. Psykoanalysen er et vigtigt udgangspunkt for Irigaray, fordi den ved sit begreb om Kvinden som ikke-mand tydeligt røber sine egne og den øvrige vestlige filosofis fortrængninger. Når den så tydeligt definerer manden som noget (= fallisk) og kvinden blot som fraver af noget (= kastreret, ikke-fallisk, ikke-mand), så afslører den, siger Irigaray, et "hul", en "mangel" ikke hos virkelighedens kvinder, men i sproget, dvs. i den vestlige kulturs imaginære og symbolske bearbejdning af den kendsgerning, at der er to køn. På den måde kalder den på spørgsmålet: Hvad vil en imaginær og symbolsk bearbejdning af kvindekroppens specificitet betyde? Det spørgsmål markerer ifølge Irigaray det selvbevidste kvindelige subjekts træden i karakter og sprog, historisk set, og i forlængelse heraf ser hun det som sit projekt at skrive kvindekroppen frem fra fortrængningen - at pege på de sprækker i de filosofiske og psykoanalytiske tekster, hvor denne ikke-tematiserede, materielle forudsætning for diskursens maskuline subjekt-position har sat sig spor. Hun insisterer på etableringen af en kvindelig subjekt-position i sproget, en kvindeligkropslig tale/skrift - på det, der især i den anglo-amerikanske Irigaray-reception er blevet identificeret som écriture féminine, selv om Irigaray strengt taget ikke selv bruger denne betegnelse (Whitford 1991, 38).

Plant specificerer Irigarays køns- og kulturkritik med et zoom ind på computerkulturen. Lige som Irigaray søger det kvindelige ved at bearbejde symptomerne på dets imaginære og symbolske fortrængning i filosofi og psykoanalyse, således skriver Plant det frem fra dets usynlige position i computerkulturen. Hvor "det kvindelige" ofte har glimret ved sit fravær i diskurser om computerkulturen (jf. billedet fra Undervisningsministeriets betænkning), kommer det i Plants tekster pludselig påtrængende til stede. For at blive i det Irigaray-inspirerede psykoanalytiske sprog kan vi sige, at det bryder voldsomt frem fra fortrængningen.

En af de tekstuelle strategier, Plant anvender for at skrive det kvindelige frem, er et ophobningsprincip. Ved kritiske læsninger og genskrivninger af et hav af forskellige fortællinger om kvinder og computerkultur sporer Plant (1997) et væld af metonymiske berøringer mellem de to. Jeg kan her blot antyde denne strategi ved at henvise til et par af de mange eksempler. Da Plants bog nemlig består af en bevidst ikkehierarkisk organiseret række af små fortællinger, unddrager den sig - lige som Irigar- 
ays tekster - principielt en opsummerende gengivelse.

Lige som Irigaray sporer kvindekroppen i filosofiens og psykoanalysens fortrængte lag - som den materialitet, der er en forudsætning for det mandlige subjekts tilblivelse, således peger Plant på cyberspace's kvindelige "infrastruktur" (Plant 1997, 36). "Infrastruktur”-begrebet er lånt fra Irigaray og referer til den akse af kønsdominans, der har konstrueret kvinder som "det andet", men Plant specificerer det i forhold til cyberkulturen. Alle de mange, lavtlønnede kvindelige arbejdere i den globalt ekspanderende elektroniske industri og servicesektor identificeres - analogt til moderkroppen hos Irigaray - som den i cyber-diskurserne ikketematiserede, men nødvendige infrastrukturelle basis for det frit kommunikerende (maskuline) cybersubjekt (Plant 1997, 74).

Endvidere tematiserer Plant massevis af berøringer mellem det teknologiske fundament for elektronisk databehandling og vævning som et gammelt kvindeligt håndværk. Hun peger på mange ligheder mellem programmeringsprocessen og væveprocessen og minder om, hvordan Charles Babbage og Ada Lovelace i det 19. århundrede konstruerede den forste egentlige computer på baggrund af en stærk inspiration fra Jacquard-væven, der netop da havde revolutioneret tekstilindustrien.

Plant fremhæver også en stærk, historisk forbindelse mellem kvinder og automatiseret arbejde. "Reglen" om, at jo mere automatiseret og computeriseret industri og servicesektor bliver, jo flere kvinder kommer ind, har, siger hun, i 1990erne ført til et veritabelt "genderquake" (Plant 1997, 37), et kønsjordskælv på arbejdsmarkedet, hvor funktioner, der traditionelt har krævet muskelstyrke, og som førhen repræsenterede mandlige jobmonopoler, nu forsvinder i takt med computernes indtog.

Med sin ophobning af små fortællinger om disse forskellige forbindelser - og mange flere til - tematiserer Plant en generel metonymisk berøring mellem kvinder og computeriserede maskiner. Begge er, viser hun, konstrueret som det andet, det inferiøre, i forhold til det "universelle man $(\mathrm{d})$ ", det hvide, maskuline, økonomisk velfunderede subjekt. Men i denne berøring er der, siger hun, basis for et posthumant fællesskab, der rummer vigtige dekonstruktive potentialer. Det er derfor her, dekonstruktionen af det universelle maskuline subjekt og dets kontrol- og styringssystemer tager afsæt hos Plant. Igangsættelsen af den i både materiel og diskursiv forstand dekonstruktive proces sker ifølge Plant, fordi disse systemer - skønt eller måske netop fordi de er konstrueret med henblik på total kontrol - er alt andet end kontrollerbare. Den indbyggede ukontrollerbarhed i systemernes komponenter (forstået som maskinerne, programmerne, kvinderne) er i Plants forståelse en vigtig dekonstruktiv mekanisme. Den modsvarer den dekonstruktive rolle, som kyborgen spiller hos Haraway. Beskrivelsen af, hvordan maskinernes og kvindernes uophørlige produktion af ukontrollerbare overskud af mening underminerer det "universelle man(d)s" subjekt-position, snor sig gennem Plants tekst. Begges principielle ukontrollerbarhed giver basis for en posthuman alliance mellem kvinder og maskiner, der skaber kaos, uorden, oprør og åbner muligheder for en ny selvbevidst digital écriture féminine, en kvindekrops-skrift, som Plant finder eksempler på hos feministiske computer-kunstnere.

\section{MELLEM KYBORGER, KVINDER OG MASKINER}

For både Haraway og Plant er posthumane fællesskaber centrale i opgøret med det "universelle man(d)", der, som billedet fra Undervisningsministeriets betænkning viser, stadig fylder meget i diskurser om cyberkulturen. Forskellen mellem de to består $i$, at Haraway ser det posthumane fællesskab blive til samtidig med en dekonstruktion af kønnet, mens kønsforskellen for den Irigaray-inspirerede Plant er en forskel, der 
gør en forskel. I Haraways version er det posthumane fællesskab en alliance mellem postkønnede kyborger; hos Plant er det baseret på metonymiske berøringer mellem kvinder, kvindelighed og computeriserede maskiner.

Jeg vil afslutningsvist opsummere denne forskel mellem Haraway og Plant indbyrdes, men også den måde, hvorpå de i fællesskab adskiller sig fra en humanistisk og naturessentialistisk køns-, kultur- og teknologikritik. Det vil jeg gøre ved at forholde dem til Dorrit Willumsens roman Programmeret til kerlighed (1981). Romanen tematiserer - ligesom Haraways og Plants tekster - kvindelighed og køn i en high-techsetting, hvor kyborger og cyberkulturelle fænomener er hverdag; men den er samtidig et skoleeksempel på den humanistiske og naturessentialistiske kritik-figur, som den posthumane kønstænkning overskrider.

I et modernistisk formsprog fortæller romanen ironisk historien om den kvindelige ingeniør Liv, der får til opgave at skabe den "perfekte kvinde-maskine", Bianca, en robot, som er "programmeret til kærlighed". Bianca skal løse samfundets voksende problemer med vold mod kvinder, som er affødt af mænds stigende frustrationer over kvindefrigørelsen. Én form for alternativ til den tingsliggjorte og maskiniserede verden, hvis dystopiske kvaliteter Bianca er et symptom på, finder romanen i en humanistisk position i form af et " $x g t e$ " menneskeligt fællesskab mellem kønnene. Konfrontationen med den "perfekte" robot-kvinde Bianca provokerer både kvinder og mænd til at finde deres glemte menneskelighed. Som en anden form for alternativ til det dystopiske high-tech-byliv, rummer romanen også en utopisk beskrivelse af et kollektiv på landet. Her artikulerer den en naturessentialistisk teknologikritik.

Med denne humanistiske og naturessentialistiske utopitænkning illustrerer romanen den form for kritikfigurer, som Haraway og Plant distancerer sig fra. Men som god litteratur har Willumsens roman også rum for andre læsninger. Dens fremstilling af Bianca kan tolkes som et fikserbillede, der skifter karakter alt efter, hvordan vi betragter det. Set fra en Harawaysk vinkel kan Biancas historie også læses som en fortælling om kyborgen, der sætter traditionelle forestillinger om køn, natur og oprindelse til debat. Når den perfekte kvinde viser sig at være en maskine, så bliver det tydeligt, at kvindeligheden er en konstruktion, der ikke har noget med nogen oprindelig kønsnatur at gøre. Set fra en Plantsk optik kan historien om den perfekte kvinde-maskine, der kommer til at leve et selvstændiggjort liv uafhængigt af sin skabers kontrol, læses som en illustration på de dekonstruktive potentialer, der ligger i den posthumane alliance mellem kvinder og maskiner. Det er Biancas funktion i romanen at bringe uorden og kaos i den verden af kontrollerede systemer, som menneskene prøver at skabe ved hjælp af maskinerne.

Ifølge den humanistiske position, som romanens slutning artikulerer, må Bianca dø efter at have provokeret menneskene til at (gen)finde deres menneskelighed. I den forstand lukker teksten af for de potentialer, den, set med Harawayske og Plantske briller, også rummer. ${ }^{2}$ Men tolket som et flertydigt fikserbillede er Bianca interessant som illustration af både en humanistisk og en posthuman feminisme.

\section{NOTER}

1. Rodney Brooks er leder af Artificial Intelligence Lab på Massachusetts Institute of Technology. Han arbejder med en "bottom-up" approach til robotkonstruktion. I stedet for at tage afsæt i den menneskelige hjernes evne til logisk tænkning (det for mennesket specielle), fokuserer han på kroppens interageren med omverdenen og den erfarings- og bevidsthedsdannelse, den afføder. Evnen til at lære af sine kropserfaringer deler mennesket med andre levende skabninger - heraf udtrykket "retreat from human specialness", som Brooks pointerede i et foredrag, jeg hørte ham holde i Society for Literature and Science, Penn. State University, Nov. 1997. 
2. Et interessant modstykke til Bianca-figuren findes i den amerikanske sf-forfatter Amy Thomsons roman Virtual Girl (1993), som jeg har analyseret andetsteds (Lykke og Braidotti 1996). Her er synsvinklen robot-kvindens og det posthumant feministiske hovedtema hendes frigørelse som selvbevidst kvinde-maskine.

\section{REFERENCER}

- Baudrillard, Jean (1994): Simulacra and Simulation, University of Michigan Press, Michigan.

- Haraway, Donna (1991): Simians, Cyborgs, and Women. The Reinvention of Nature, Free Association Books, London.

- Haraway, Donna (1992): The Promises of Monsters: A Regenerative Politics for Inappropriate/d Others. In Lawrence Grossberg, Cary Nelson, Paula Treichler: Cultural Studies, Routledge, London/New York.

- Haraway, Donna (1997): Modest_Witness@ Second_Millenium.FemaleMan@__Meets_Onco Mouse $^{\mathrm{TM}}$. Feminism and Technoscience. Routledge, London/New York.

- Irigaray, Luce (1974): Speculum de l'autre femme, Les Éditions de Minuit, Paris.

- Irigaray, Luce (1977): Ce sexe qui n'en est pas un, Les Éditions de Minuit, Paris.

- Lykke, Nina (1996): Kyborg eller gudinde? Feministiske dilemmaer i det sene 20. århundredes øko- og teknokritik. In Kvinder, Køn og Forskning 1996/4.

- Lykke, Nina og Rosi Braidotti (1996): Between Monsters, Goddesses and Cyborgs. Feminist Confrontations with Science, Medicine and Cyberspace, ZED-Books, London.

- Markussen, Randi (1997): Køn i cyberspace. In Kvinder, Køn og Forskning 1998/1.

- Plant, Sadie (1997): Zeros + Ones. Digital Women + The New Technoculture. Fourth Estate, London.
- Russ, Joanna (1975): the female man, Bantam Books, New York.

. Thomson, Amy (1993): Virtual Girl, Ace Books, New York.

- Undervisningsministeriet (1993): Teknologistøttet undervisning (Fjernundervisning). Betænkning nr. 1253. Undervisningsministeriet, København.

- Whitford, Margaret (1991): Philosophy in the Feminine, Routledge, London/New York.

- Willumsen, Dorrit (1981): Programmeret til karlighed. Vindrose, København.

\section{SUMMARY}

The article is a discussion of two cyberfeminists, Donna Haraway and Sadie Plant, and their innovative posthuman approaches to feminist deconstruction of the masculine connotations of cyberculture. The author compares Haraway's cyborg-figure that represents a post-gender, post-origin and postnature position to the alliance of women and machines, promoted by Plant, who, inspired by Luce Irigaray, attempts to inscribe an embodied feminine subject in cyberspace and trace a digital écriture féminine. In conclusion the article profiles the posthuman approaches of Haraway and Plant with the bumanist critique of the social relations of gender, culture and technology, which is articulated in a "cyborg"-novel by Dorrit Willumsen "Programmeret til karlighed" (Programmed to Love) (1981).

Nina Lykke, lektor, dr. phil., Syddansk Universitet, Odense 